\title{
Antiviral propierties of 5,5'-dithiobis-2- nitrobenzoic acid and bacitracin against T-tropic human immunodeficiency virus type 1
}

\author{
Humberto H Lara ${ }^{1 *}$, Liliana Ixtepan-Turrent', Elsa N Garza-Treviño', Samantha M Flores-Teviño1, Gadi Borkow² and \\ Cristina Rodriguez-Padilla ${ }^{1}$
}

\begin{abstract}
Bacitracin and the membrane-impermeant thiol reagent 5,5'-dithiobis-2-nitrobenzoic acid (DTNB) are agents known to inhibit protein disulfide isomerase (PDI), a cell-surface protein critical in HIV-1 entry therefore they are fusion inhibitors (FI). Here we investigated the possibility that Bacitracin and or DTNB might have other antiviral activities besides Fl. By means of residual activity assays, we found that both compounds showed antiviral activity only to viruses T-tropic HIV-1 strain. Cell-based fusion assays showed inhibition on HeLa-CD4-LTR- $\beta$-gal (CD4) and HL2/3 cells treated with Bacitracin, and DTNB with the latest compound we observed fusion inhibition on both cells but strikingly in $\mathrm{HL} 2 / 3$ cells (expressing Env) indicating a possible activity on both, the cell membrane and the viral envelope. A time-of-addition experiment showed that both compounds act on HIV entry inhibition but DTNB also acts at late stages of the viral cycle. Lastly, we also found evidence of long-lasting host cell protection in vitro by DTNB, an important pharmacodynamic parameter for a topical microbicide against virus infection, hours after the extracellular drug was removed; this protection was not rendered by Bacitracin. These drugs proved to be leading compounds for further studies against HIV showing antiviral characteristics of interest.
\end{abstract}

\section{Introduction}

The pandemic of Human Immunodeficency Virus Tipe 1 (HIV-1) infection, the cause of AIDS, is a public health issue and ranks among the greatest infectious disease scourges in history [1]. There were more than 33.3 million people worldwide with HIV-1 infection or AIDS, according to estimates by the Joint United Nations Programme on HIV/AIDS 2009 (UNAIDS).

The use of highly active antiretroviral therapy has dramatically reduced morbidity and mortality among patients infected with HIV-1 [2,3]. However, the success of antiretroviral treatment is frequently limited by the emergence of HIV-1 drug resistance. Several researchers have attempted to develop various virucidal agents to inactivate the cell-free virions and therefore prevent the sexual transmission of HIV-1 [4-7].

\footnotetext{
* Correspondence: dr.lara.v@gmail.com

'Laboratorio de Inmunología y Virología, Departamento de Microbiología e Inmunología, Universidad Autonoma de Nuevo Leon, San Nicolas de los

Garza, Nuevo Leon, Mexico

Full list of author information is available at the end of the article
}

In the early event of HIV-1 infection, the viral glycoprotein gp120 attaches the virus to the cell by binding to its receptor CD4 on cells of the host's immune system. Another cell-surface protein was found to be involved in HIV-1 entry, the oxidoreductase protein disulfide isomerase (PDI) $[8,9]$. PDI has been described to play a role in host cell uptake of some toxins, bacteria, parasite [10] and virus modulating the exchange of protons between a cell-surface associated donor (PDI) and viral proteins by catalyzes thiol-disulfide $\mathrm{SH} /-\mathrm{S}-\mathrm{S}$ interchange [11,12].

Besides the observation that PDI inhibition blocks the HIV replicative cycle [13] by conformational changes, gp120 interacts with the enzyme PDI and the chemokine co-receptors form a PDI-CD4-gp120-chemokine complex also prevent HIV envelope mediated fusion [9] PDI can reach the complex and reduce disulfide bonds in gp120 [14] that involves cleavage of two of the nine disulfide bonds of gp120 [15-17], which causes key conformational changes in gp120 and activate gp41 enhancing the fusogenic potential of the viral envelope. It has
Ciomed Central

C 2011 Lara et al; licensee BioMed Central Ltd. This is an Open Access article distributed under the terms of the Creative Commons Attribution License (http://creativecommons.org/licenses/by/2.0), which permits unrestricted use, distribution, and reproduction in any medium, provided the original work is properly cited. 
been shown that inhibition of HIV-1 entry can be brought about by introducing membrane impermeant sulfhydryl agents that can block the redox function of PDI, acting inhibiting PDI, to prevent the viral entry $[8,18]$.

Studies reported that the thiol reagent 5,5'-dithiobis-2nitrobenzoic acid (DTNB) $[8,9]$, and Bacitracin were commonly used as inhibitors of PDI activity. These agents will stop the generation of two free thiols in a gp120 and an oxidized form of CXXC motif in PDI, blocking HIV-1 infection [19]. More recently, were showed that these inhibitors altered the HIV receptordependent gp41-mediated fusion process per se at a post-CD4 binding step, particularly DTNB, prevents gp41 from assuming the 6-helix bundle conformation that drives fusion [15-17], but the effect was temporally, only was observed when the agents were present at the time of virus-cell interaction $[8,9]$. It is speculated that inhibition if HIV infectivity by Bacitracin could arise because of one of two effects [20]. First, Bacitracin could inhibit PDI by competing with substrate binding, especially by competing for the substrate-binding site on the b' domain. Second, PDI activity could be inhibited by the metal ions that bacitracin is known to bind. These metal ions could be coordinated by the active site cysteines of the catalytic domains of PDI, decreasing their activity.

It was reported that the DTNB causes 100\% inhibition of soluble PDI activity at $1.0 \mathrm{mM}$ concentration $[8,9]$. The mechanisms is not yet been completely elucidated however, it has been reported the DTNB acting two conformations, there were, three, two hydrogen bonds formed; thiol group of Cys37 and backbone-oxygen atom of Phe80 in PDI enzyme interacts with the two different atom of sulfur (S2 and S1) in DTNB and side chain nitrogen atom of Arg101 was also involved in the hydrogen bond interaction with O3 atom of DTNB [19]

Previous studies described molecular docking simulation to investigate the binding mechanisms of action for Bacitracin and DTNB or fusion inhibition by reorganization of the conformation of Env, however the action as antiviral and the importance of HIV receptors (CXCR4 on CD4+ lymphocytes) has not been clearly established. For that reason and searching for other antiviral activities that these leading compounds might have, we also tested if these compounds have long lasting protection against viral infection on uninfected host cells even hours after the compounds were removed form the media which is an important pharmacodynamic parameter investigated during the development of a topical microbicide agent. In addition we evaluated the stages of the viral cycle to elucidate the target sites of these compounds.

\section{Methods}

\section{Reagents, cells and HIV-1 isolates}

The following reagents were obtained through AIDS Research and Reference Reagent Program, NIH: HeLaCD4-LTR- $\beta$-gal (CD4) cells from Dr. Michael Emerman; HL2/3 (Env) cells from Dr. Barbara K. Felber and Dr. George N. Pavlakis; HIV-1 ${ }_{\mathrm{IIIB}}$, HIV-1 $1_{\mathrm{BaL}}$ and Fusion Inhibitor T-20, Integrase Inhibitor 118-D-24 and Protease Inhibitor Amprenavir from Dr. Suzanne Gartner, Dr. Mikulas Popovic and Dr. Robert Gallo. DTNB and Bacitracin were obtained from Sigma-Aldrich. UC781, a NNRTI, was kindly donated by Dr. Gadi Borkow.

\section{Cytotoxicity assays}

A stock solution of DTNB and Bacitracin was two-fold diluted to desired concentrations in growth medium and subsequently added into wells containing $5 \times 10^{4} \mathrm{HeLa}$ CD4-LTR- $\beta$-gal cells. Microtiter plates were incubated at $37^{\circ} \mathrm{C}$ in a $5 \% \mathrm{CO}_{2}$ air humidified atmosphere for 24 hours. Assessments of cell viability were carried out using a CellTiter-Glo ${ }^{\circledR}$ Luminescent Cell Viability Assay (Promega). Cytotoxicity was evaluated based on the percentage cell survival relative to the infection obtained in the absence of any compound.

\section{Virucidal activity assays}

Serial two-fold dilutions of DTNB, Bacitracin or just media as control were added to HIV-1 $1_{\text {IIIB }}$ or $\mathrm{HIV}-1_{\mathrm{BaL}}$ cell-free virus. After incubation for $5 \mathrm{~min}$ at room temperature, the mixtures of compounds with virus were centrifuged three times at 10,000 rpm, the supernatant fluids removed, and the pellets washed three times. The final pellets were resuspended in DMEM and placed into 96-well plates with HeLa-CD4-LTR- $\beta$-gal cells. The cells were incubated in a $5 \% \mathrm{CO}_{2}$ humidified incubator at $37^{\circ} \mathrm{C}$ for $24 \mathrm{~h}$. Assessment of HIV-1 infection was performed with the Beta-Glo Assay System. The percentage of residual infectivity after DTNB, Bacitracin or media as control was calculated with respect to the control. The $50 \%$ inhibitory concentration $\left(\mathrm{IC}_{50}\right)$ was defined according to the percentage of infectivity inhibition relative to the positive control.

\section{Cell-based fusion assay}

HeLa-derived HL2/3 cells, which express the HIV-1 $1_{\text {HXB2 }}$ Env, Tat, Gag, Rev, and Nef proteins, were co-cultured with HeLa-CD4-LTR- $\beta$-gal cells at a 1:1 cell density ratio $\left(5 \times 10^{4}\right.$ cells/well each) for $24 \mathrm{~h}$ in the absence or presence of two-fold dilutions of DTNB, Bacitracin, UC781, and T-20 in order to examine whether the compounds interfered with the binding process of HIV-1 Env and the CD4 receptor. Also, both HeLa-CD4-LTR$\beta$-gal and HL2/3 cells were exposed independently only 
30 minutes to the aforementioned compounds and then washed twice thoroughly to eliminate residual compound before co-cultivating with the other cell line. Upon fusion of both cell lines, the Tat protein from HL2/3 cells activates $\beta$-galactosidase indicator gene expression in HeLa-CD4-LTR- $\beta$-gal cells ${ }^{20}$. $\beta$-gal activity was quantified with the Beta-Glo Assay System (Promega). The percentage of inhibition of HL2/3-HeLa $\mathrm{CD} 4$ cell fusion was calculated with respect to the positive control of untreated cells.

\section{Time-of-addition experiments}

HeLa-CD4-LTR- $\beta$-gal cells were infected with $10^{5}$ $\mathrm{TCID}_{50}$ of HIV-1 $1_{\text {IIIB }}$ cell-free virus with a 0.2-0.5 MOI. Bacitracin (3.5 mM), DTNB (6 mM), T-20 (100 $\mu \mathrm{M})$, UC781 (70 nM), 118-D-24 (120 $\mu \mathrm{M})$ and Amprenavir $(0.1 \mathrm{mM})$ were then added upon HIV-1 inoculation (time zero) or at various time points post-inoculation. The reference compounds were added at a concentration several times their $\mathrm{EC}_{50}$ required to reduce by $50 \%$ the cytopathicity of HIV-1 $1_{\text {IIIB }}$. Infection inhibition was quantified after $24 \mathrm{~h}$ of incubation, by measuring $\beta$-gal activity of the target cells with the Beta-Glo Assay System.

\section{Cell-Protection Assays}

HeLa-CD4-LTR- $\beta$-gal cells were incubated with DTNB $(12.6 \mathrm{mM})$ or Bacitracin $(5.3 \mathrm{mM})$ for 30 minutes and subsequently the cells were washed with PBS three times. Then, the cells were infected with $10^{5} \mathrm{TCID}_{50}$ of HIV- $1_{\text {IIIB }}$ cell-free virus with a 0.2-0.5 MOI at different times $(1,3,6,10$ and $24 \mathrm{~h})$ of exposure to the drugs.
The inhibition of infection was quantified after $24 \mathrm{~h}$ by measuring $\beta$-gal activity with the Beta-Glo Assay System.

\section{Statistical analysis}

Graphs were done with SigmaPlot 10.0 software and the values shown are means \pm standard deviations from three separate experiments, each of which was carried out in duplicate.

\section{Results}

Range of virucidal activity

To study the effect that DTNB or Bacitracin have over the virus itself, $\mathrm{M}$-tropic $\left(\mathrm{HIV}-1_{\mathrm{BaL}}\right)$ and T-tropic $\left(\mathrm{HIV}-1_{\mathrm{IIIB}}\right)$ isolates were treated with different concentrations of PDI inhibitors the mixtures were centrifuged three times at $10,000 \mathrm{rpm}$ in an eppendrof centrifuge. After removal of the supernatant fluids with or without (control) compounds, the pellets were washed three times. The final pellets were placed into 96-well plates with HeLa-CD4LTR- $\beta$-gal cells. Assessment of HIV- 1 infection was made with a luciferase-based assay. The percentage of residual infectivity after treatment was calculated with respect to the positive control of untreated virus. The assay was performed in triplicate; the data points represent the mean, and the solid lines are nonlinear regression curves done with SigmaPlot 10.0 software.by centrifugation, the residual infectivity of the cell-free viruses was quantified by a luciferase-based assay using indicator cell lines. As shown in Figure 1(A-B), pretreatment with Bacitracin or DTNB reduced the infectivity of $\mathrm{T}$-tropic $\left(\mathrm{HIV}-1_{\mathrm{IIIB}}\right)$ after just
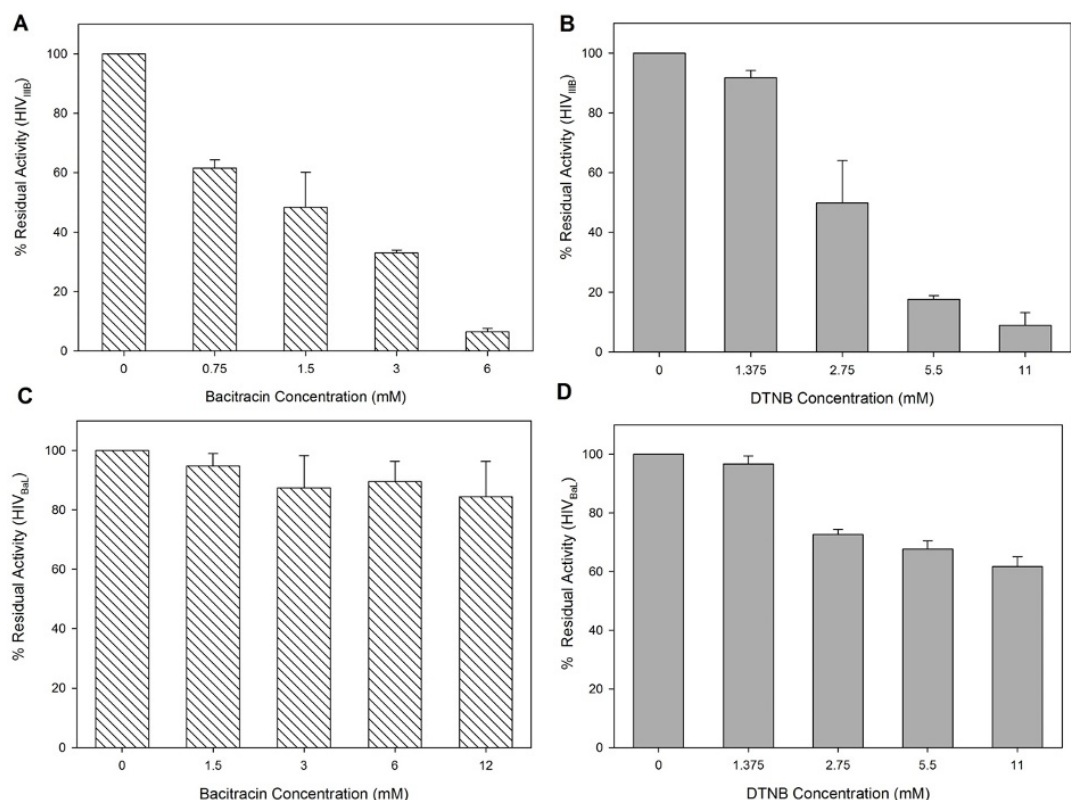

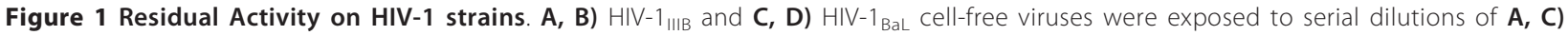
Bacitracin and $\mathbf{B}, \mathbf{D})$ DTNB for 5 minutes. The viruses were then ultracentrifuged, washed three times and added to HeLa-CD4-LTR- $\beta$-gal cells After 24 hours, $\beta$-gal activity was measured. Percentage values are relative to the positive control (no compound pretreatment). 
5 min of exposure. However, both compounds pretreatment did not show a significant inhibition activity over Mtropic $\left(\mathrm{HIV}-1_{\mathrm{BaL}}\right)$. The concentration of Bacitracin and DTNB at which HIV-1 $1_{\text {IIIB }}$ infectivity was inhibited by $50 \%$ $\left(\mathrm{IC}_{50}\right)$ was $1.18 \mathrm{mM}$ and $2.60 \mathrm{mM}$, respectively, Bacitracin showed a higher therapeutic index (TI), more than three times higher than the TI showed by DTNB. However, cytotoxic concentration which $50 \%$ of cell dead $\left(\mathrm{CC}_{50}\right)$ were 30.37 and 19.77 for Bacitracin and DTNB respectly (Table 1).

\section{Inhibition of Env/CD4-mediated membrane fusion}

A cell-based fusion assay was used to mimic the gp120CD4-mediated fusion process between HIV-1 and the host cell. The effector cells were HL2/3 cells, which express HIV-1 Env on their surfaces and Tat protein in their cytoplasms [21], and experiments were performed to determinate whether DTNB and Bacitracin tended to act directly either on the HeLa-CD4-LTR- $\beta$-gal (CD4) cells or HL2/3 (Env) cells or boths cells when inhibiting fusogenic activity. When HeLa-CD4-LTR- $\beta$-gal (CD4) cells were first exposed to the compounds and then HL2/3 (Env) cells were added, both Bacitracin (Figure $2 \mathrm{~A}$ ) and DTNB (Figure 2B) blocked fusion in a dose response manner between both cells; the same happened when HL2/3 (Env) cells were first exposed to the compounds and then HeLa-CD4-LTR- $\beta$-gal (CD4) cells were added (Figure 2A-B). A significant lower dose of Bacitracin was required to reach an observable decrease in fusogenic activity in HeLa-CD4-LTR- $\beta$-gal (CD4) cells than the dose needed to pretreat HL2/3 (Env) cells ( $\mathrm{p}=$ 0.09); on the other hand, a significant lower dose of DTNB was needed to inhibit the fusogenic activity when HL2/3 (Env) cells were pretreated compared to the pretreatment of HeLa-CD4-LTR- $\beta$-gal (CD4) cells $(\mathrm{p}=$ 0.009 ). In addition the assays were performed, while the exposure of Bacitracin and DTNB to HeLa-CD4-LTR- $\beta$ gal (CD4) or HL2/3 (Env) cells, separately, during 30 minutes only, following by extracellular compound removal by washing the cells. Results showed a significant lower dose was required to inhibit fusogenic activity when HL2/3 (Env) cells were pretreated with DTNB during 24 hours than the 30 minutes pretreatment before mixing to HeLa-CD4-LTR- $\beta$-gal (CD4) cells exposure $(p=0.007)$. Our data, as well as data from others laboratories, support the concept that thiol/

Table $1 \mathrm{CC}_{50}$ and virucidal IC $\mathrm{C}_{50}$ values for HIV-1 strains

\begin{tabular}{|c|c|c|c|c|}
\hline & \multirow[t]{2}{*}{$\mathrm{CC}_{50}(\mathrm{mM})$} & \multicolumn{2}{|c|}{$\mathrm{I} C_{50}(\mathrm{mM})$} & \multirow{2}{*}{$\begin{array}{c}\mathrm{TI} \\
\left(\mathrm{HIV}-1_{\mathrm{IIIB}} / \mathrm{HIV}-1_{\mathrm{Ba}-\mathrm{L}}\right)\end{array}$} \\
\hline & & HIV-1 $1_{\text {IIIB }}$ & HIV-1 ${ }_{\text {Ba-L }}$ & \\
\hline Bacitracin & 30.37 & 1.18 & $>30.37$ & $25.73 /<1$ \\
\hline DTNB & 19.77 & 2.60 & > 19.77 & $7.60 /<1$ \\
\hline
\end{tabular}

disulfide rearrangement in gp120 catalyzed by PDI occurs post-CD4 engagement [17]. Known antiretroviral drugs were used as controls, such as UC781 (NNRTI), which did not inhibit cell fusion in these cell-based fusion assays (Figure 2C), and T-20 (FI), which did inhibit cell fusion in all assays, except when exposed to HeLa-CD4-LTR- $\beta$-gal (CD4) cells for only 30 minutes (Figure 2D).

\section{Time (Site) of Intervention}

To further determine the antiviral target of Bacitracin and DTNB, a time-of-addition experiment was performed using a single cycle infection assay. Several antiretroviral drugs were chosen as controls as they point out different stages of the viral cycle (fusion or entry, retrotranscription, protease activity, and integration to the genome). As seen in Figure 3(A-F), the antiviral activity of T-20, UC781, 118-D-24 and Amprenavir started to decline after the cycle stage that the antiviral target has passed. The fusion inhibitor's activity declined after $2 \mathrm{~h}$ (Figure 3C), RT inhibitor after $15 \mathrm{~h}$ (Figure $3 \mathrm{D}$ ), integrase inhibitor after $18 \mathrm{~h}$ (Figure 3E), and protease inhibitor after $18 \mathrm{~h}$ (Figure 3F). Bacitracin retained its antiviral activities during $2 \mathrm{~h}$ (Figure 3A) as a fusion inhibitor after the HIV inoculation. On the other hand, 15 hours after HIV inoculation, the antiviral activity of DTNB started to decrease (Figure 3B), which is the time period of viral entry and integration stages. Also, the antiviral activity of DTNB regained strength at 24 hours post-HIV inoculation, which corresponds to viral protease stage [22].

\section{Cell-Protection Assays}

HeLa cells were pretreated with Bacitracin and DTNB for 30 minutes and subsequently exposed to HIV-1 $1_{\text {IIIB }}$ at different post-infection times until 48 hours to measure cell protection without extracellular drug. As shown in Figure 4(A), after extracellular Bacitracin is removed, there is no cellular protection against infectivity, while DTNB protection against infection to cells after removal of extracellular drug, was retained until 10 hours.

\section{Discussion}

PDI inhibition blocks the HIV early replicative cycle $[7,13]$ and HIV entry occur at 3 different steps: CD4 binding, the gp41 mediated membrane fusion process, and during uncoating events. Thus conformational changes, gp120 interacts with the enzyme PDI and the chemokine co-receptors form a PDI-CD4-gp120-chemokine complex also prevent HIV envelope mediated fusion to the host cell $[8,9,14,17,23]$.

DTNB and Bacitracin are PDI inhibitors that previously reported activity against HIV-1 T-tropic strains, which have CXCR4 co-receptor dependence (CXCR4) $[8,9]$. 

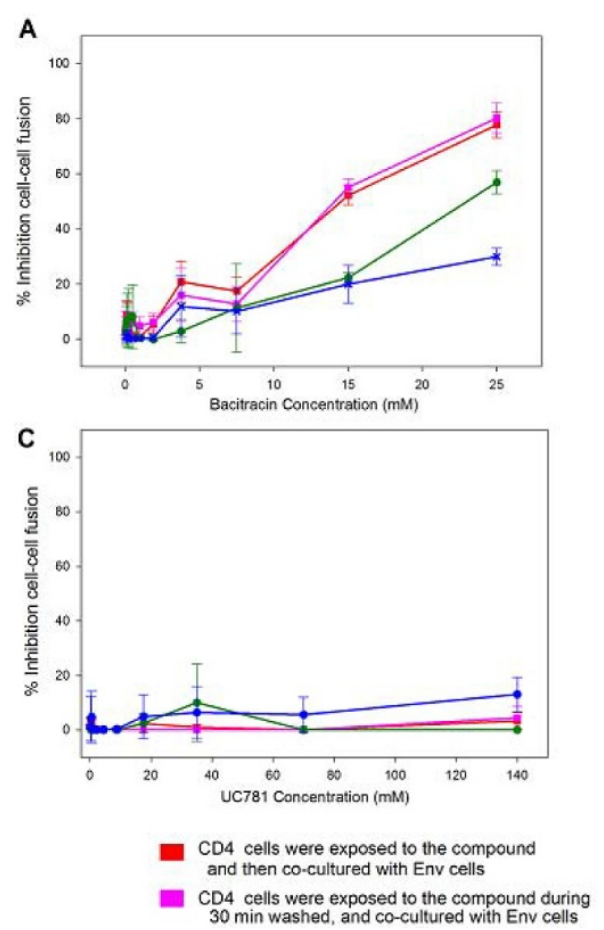
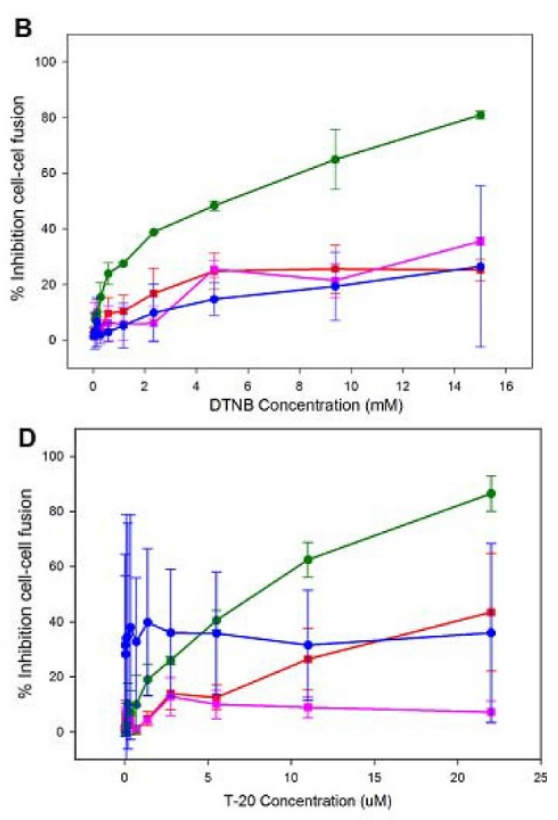

Env cells were exposed to the compound and then co-cultured with CD4 cells

Env cells were exposed to the compound during 30 min washed, and co-cultured with CD4 cells

Figure 2 Inhibition of Env/CD4-mediated membrane fusion. $\beta$-gal activity was measured after CD4 and Env cells were co-cultured when exposed to A) Bacitracin, B) DNTB, C) UC781 and D) T-20, in different circumstances: (red) CD4 cells were exposed to the compound and cocultured with Env cells for 24 hours. (green) Env cells were exposed to the compound and co-cultured with CD4 cells for 24 hours. (purple) CD4 cells were exposed to the compound for 30 minutes, washed, and co-cultured with Env cells for 24 hours. (blue) Env cells were exposed to the compound for 30 minutes, washed, and co-cultured with CD4 cells for 24 hours. Percentage values are relative to the positive control (no treatment). The data represent the means \pm standard deviations from three separate experiments, each of which was carried out in duplicate.

DTNB is a sulfhydryl blocker that covalently reacts with the catalytic sites of PDI and abolishes its capacity for cleaving disulfides, whereas Bacitracin inhibits both its reductive and oxidative functions [14,24]. In this paper we found that both compounds showed antiviral and virucidal activities in a dose-dependent manner. However T-tropic ( $\mathrm{HIV}_{\text {IIIB }}$ ) strains which has CXCR4 co-receptor were susceptible to both compounds and not to the M-tropic $\left(\mathrm{HIV}_{-\mathrm{BaL}}\right)$ strain (Figure 1A-D) due probably at the increased of negative charge ( $\mathrm{T}$-tropic) in variable region (V3) of human immunodeficiency virus type 1 (HIV-1) envelope gp120 subunit participates in determination of viral infection coreceptor tropism [25-27].

Furthermore, cell-based fusion assays [28] were performed for these compounds, using HeLa-CD4-LTR- $\beta$ gal cells [29] and H2/3 (Env-expressing) cells [21], where co-culture expressing cells results in efficient cell fusion within 6-12 hours. We found that both Bacitracin and DTNB showed inhibition of cell-cell fusion in a dose-dependent manner when exposed to HeLa-CD4LTR- $\beta$-gal cells (Figure $2 \mathrm{~A}-\mathrm{B}$ ). These results are similar to those presented by Fenouillet et al [14], where PDI inhibitors as well as anti-PDI antibodies, were used to inhibit cell-cell fusion assays. However exposure to HeLa-CD4-LTR- $\beta$-gal cells showed no significant difference on cell-cell fusion on either the 24 hour or the 30 minute exposure assay which is the time the process of conformational changes of gp120 after CD4 bonding takes place [30]. Alternatively, long-term exposure (24 hours) of DTNB on HL2/3 (Env-expressing) cells and then mixing them with CD4 cells showed significant inhibition of cell-cell fusion as showed in Figure 2B. This effect of Bacitracin and DTNB markedly on Env expressing cells has never been reported.

Also, our findings indicate that Bacitracin and DTNB act differently on HeLa-CD4-LTR- $\beta$-gal cells and HL2/3 (Envexpressing) cells, given that Bacitracin has more effect on HeLa-CD4-LTR- $\beta$-gal cells but less effect against HL2/3 (Env-expressing) cells fusion's activity, however DTNB has cell-cell fusion inhibition effect on HeLa-CD4-LTR- $\beta$-gal cells but predominantly on HL2/3 (Env-expressing) cells. This data confirmed that both compounds act on the HIV receptor dependent gp 41 mediated fusion process per se through inhibition of a post-CD4 binding step that has antiviral effects and virucidal action [14]. However our results with Bacitracin showed that has a better inhibition 

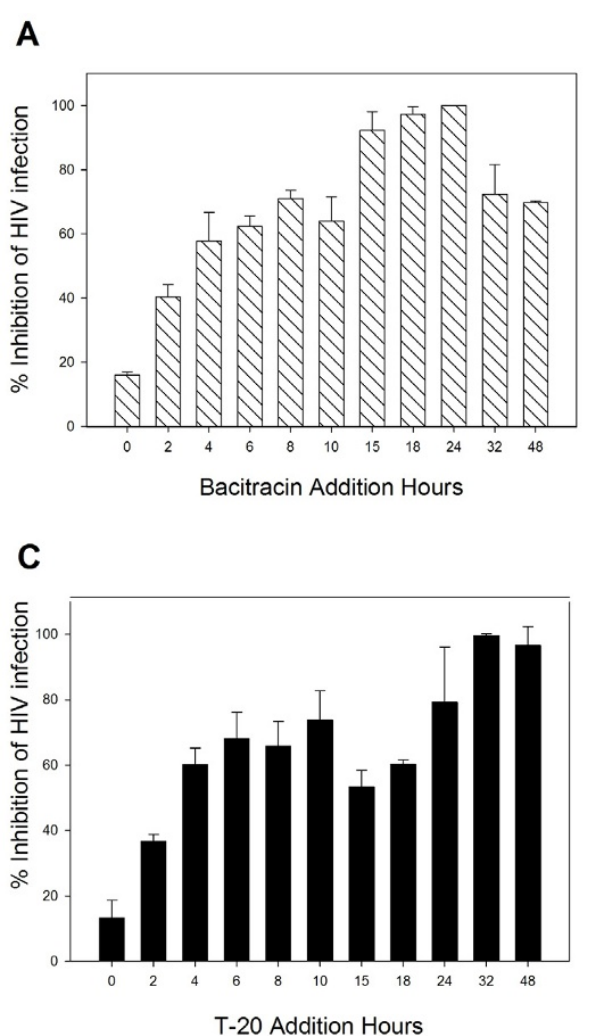

E

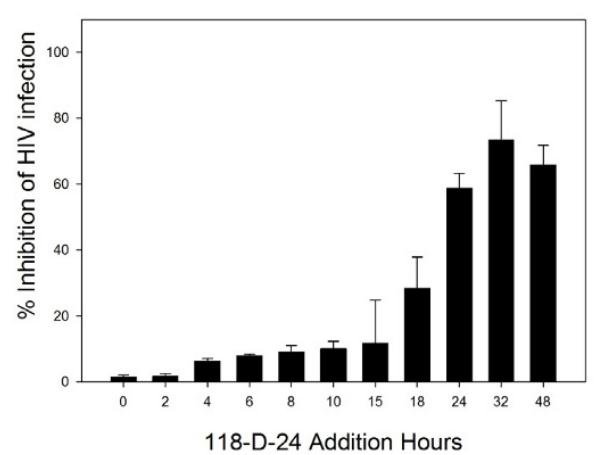

B

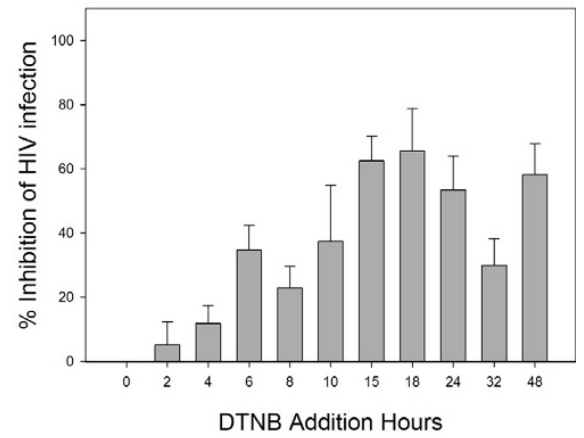

D

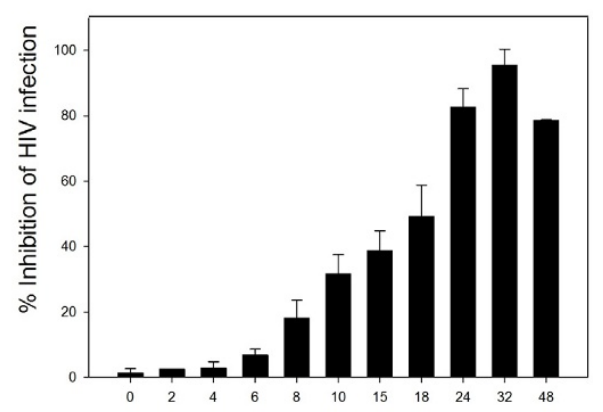

UC781 Addition Hours

$\mathbf{F}$

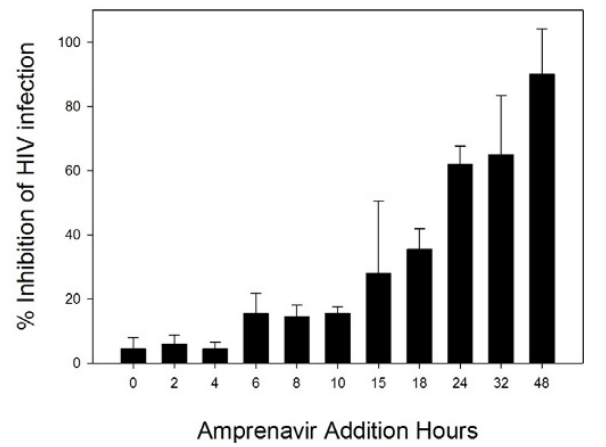

Figure 3 Time of Intervention in HIV-1 Life Cycle. HeLa/CD4-LTR- $\beta$-gal cells were infected with HIV-1 ${ }_{\text {IIIB }}$ Cell-free virus before A) Bacitracin (3.5

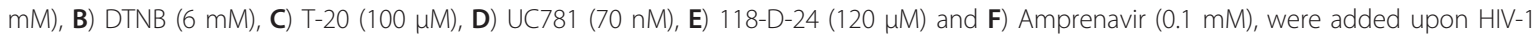
inoculation (time zero) or at various time points post-inoculation and $\beta$-gal activity was measured following 24 hr of incubation. Percentage values are relative to the positive control (no treatment). The data represent the means \pm standard deviations from three separate experiments, each of which was carried out in duplicate.

effect on the host CD4 cell acting only as fusion inhibitor on CD4 cells [20] but also having an inhibition effect on env expressing cells.

In addition, to further determine the antiviral target of Bacitracin and DTNB, a time-of addition experiment was used to delimit the stage(s) of the viral life cycle that is blocked by these compounds separately, comparing it with several antiretroviral drugs as controls that point out different stages of the viral cycle [31-36]
(Figure 3C-F). Our findings suggest that Bacitracin inhibits HIV-1 infection at stage of viral entry or fusion (Figure 3A), however DTNB acts at a time period between and including viral entry and other later stages (Figure 3B). DTNB results shows that has probably an antiviral function affect on protease activity, this results are also according to Lebon [22]. This is the first time, to our knowledge, that the activity of this compound has been associated to HIV-1 life cycle stages besides 


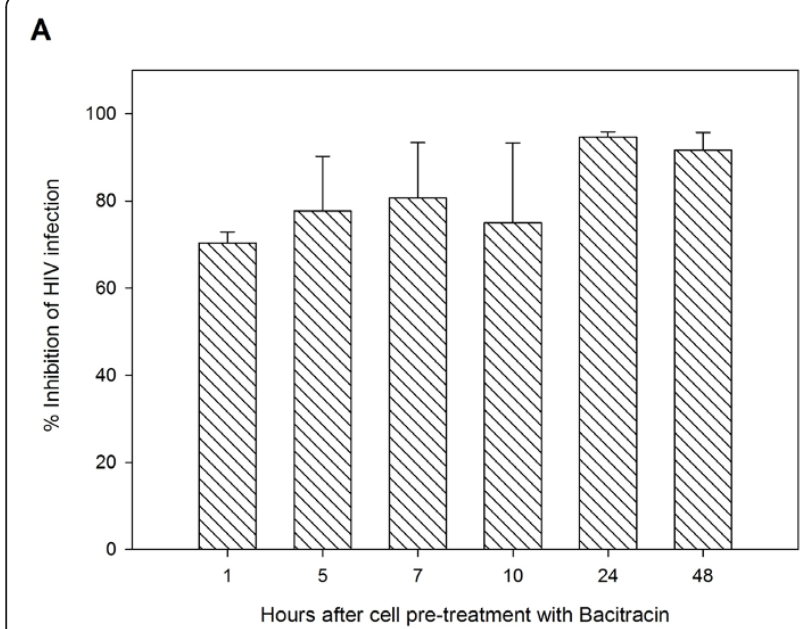

B

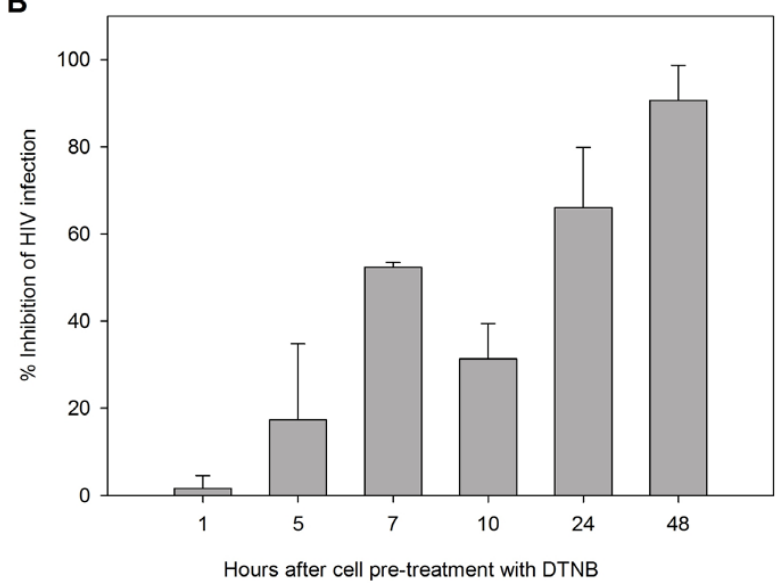

Figure 4 Cell Protection Against HIV-1 Infection. $\beta$-gal activity was measured after HeLa/CD4-LTR- $\beta$-gal cells were exposed to A) Bacitracin (5.3 mM) and B) DTNB (12.6 mM) for 30 minutes, washed and exposed to HIV-1 $1_{\text {IIB }}$ cell-free virus at various time points post-treatment. Percentage values are relative to the positive control (no treatment). The data represent the means \pm standard deviations from three separate experiments, each of which was carried out in duplicate.

fusion. However studies has shown that down regulation of PDI using small interfering RNA had only a small effect on infection or cell fusion mediated by HIV-1, suggesting that other thiol active enzymes at the cell surfaces are involved in reduction of the HIV envelope glycoprotein, that is therefore an interesting result.

Lastly, in order to provide a barrier to infection by residual active virus on uninfected cells, we evaluated the long-term effectiveness of the compound, which is an important pharmacodynamic parameter tested for the development of a topical agent [37], and is defined as the length of time that infection is suppressed following brief exposure to the antiviral agent. Ideally, a microbicide should remain effective for several hours after topical application. These compounds should be able to give cell protection for several hours after the removal of the extracellular drug [38] Although Bacitracin did not show cell protection (Figure 4A), DTNB on the other hand, showed lasting cell protection (50\% infection inhibition) even 10 hours after compound was washed and removed from the indicator cells (Figure 4B). These results are consistent with a time-of addition experiment that showed that DTNB act after viral entry suggesting that DTNB somehow bonds to target cell strongly and though DTNB's PDI bonding activity is not discarded, other cell sites could be participating. Previous reports showed DTNB only has effect when anti-PDI was present at the time of virus-cell interaction (Ryser et al., 1994). Our results demonstrated that exposure of uninfected cells to DTNB renders these cells refractory to subsequent HIV-1 infection, even in the absence of a continued extracellular presence of the drug. Thus, DTNB may serve to minimize the sexual transmission of HIV-1 from infected to noninfected individuals.

In summary, although both, Bacitracin and DTNB, are classified as fusion inhibitors of cell PDI, our findings suggest new data. The data presented here are novel in that they prove that both Bacitracin and DTNB (besides acting on cell PDI), are also virucidal agents against $\mathrm{T}$ tropic HIV-1 infection, and DTNB acts not only at early viral cycle stages but also at late stages with long lasting effects on the CD4 cells.

Based on our results and the above requirements, DTNB could be considered as a leading compound to further studies to determine their potential use as therapeutic agents in HIV-1 infection, especially due to their virucidal and fusion inhibitor properties.

\section{Acknowledgements}

The following funding sources supported the data collection process: the Programa de Apoyo a la Investigacion en Ciencia y Tecnologia (PAICyT) of the Universidad Autonoma de Nuevo Leon, Mexico, and the Consejo Nacional de Ciencia y Tecnologia (CONACyT) of Mexico.

\section{Author details}

'Laboratorio de Inmunología y Virología, Departamento de Microbiología e Inmunología, Universidad Autonoma de Nuevo Leon, San Nicolas de los Garza, Nuevo Leon, Mexico. 'Hama'ayan 4, Ligad Center 2, Modi'in 71700, Israel.

\section{Authors' contributions}

All authors read and approved the final manuscript. HHL participated in the conception and experimental design of the in vitro HIV-1 manipulation and infectivity assays, in analysis and interpretation of the data, and in writing and revision of this report. ENG participated in the conception and design of the in vitro HIV-1 manipulation and infectivity assays, in analysis and interpretation of the data, and in writing and revision of this report. LIT participated in collection of in vitro HIV-1 manipulation and infectivity assays. GB and CR-P. participated in the experimental design of this research.

\section{Competing interests}

The authors declare that they have no competing interests.

Received: 16 November 2010 Accepted: 24 March 2011

Published: 24 March 2011 


\section{References}

1. Fauci AS: The AIDS epidemic-considerations for the 21st century. N Engl J Med 1999, 341(14):1046-1050.

2. Palella FJ Jr, Delaney KM, Moorman AC, et al: Declining morbidity and mortality among patients with advanced human immunodeficiency virus infection. HIV Outpatient Study Investigators. N Engl J Med 1998, 338(13):853-860.

3. Vittinghoff E, Scheer S, O'Malley P, Colfax G, Holmberg SD, Buchbinder SP: Combination antiretroviral therapy and recent declines in AIDS incidence and mortality. J Infect Dis 1999, 179(3):717-720.

4. Balzarini J, Naesens L, Verbeken $E$, et al: Preclinical studies on thiocarboxanilide UC-781 as a virucidal agent. AIDS 1998, 12(10):1129-1138.

5. Fauci AS: Multifactorial nature of human immunodeficiency virus disease: implications for therapy. Science 1993, 262(5136):1011-1018.

6. Pantaleo G, Graziosi C, Fauci AS: The role of lymphoid organs in the pathogenesis of HIV infection. Semin Immunol 1993, 5(3):157-163.

7. Van DL, Rosenberg ZF: Microbicides and barrier methods in HIV prevention. AIDS 1999, 13(Suppl A):S85-S92.

8. Ryser HJ, Levy EM, Mandel R, DiSciullo GJ: Inhibition of human immunodeficiency virus infection by agents that interfere with thioldisulfide interchange upon virus-receptor interaction. Proc Natl Acad SCi USA 1994, 91(10):4559-4563.

9. Gallina A, Hanley TM, Mandel R, et al: Inhibitors of protein-disulfide isomerase prevent cleavage of disulfide bonds in receptor-bound glycoprotein 120 and prevent HIV-1 entry. J Biol Chem 2002, 277(52):50579-50588

10. Santos CX, Stolf BS, Takemoto PV, et al: Protein disulfide isomerase (PDI) associates with NADPH oxidase and is required for phagocytosis of Leishmania chagasi promastigotes by macrophages. J Leukoc Biol 2009, 86(4):989-998.

11. Edman JC, Ellis L, Blacher RW, Roth RA, Rutter WJ: Sequence of protein disulphide isomerase and implications of its relationship to thioredoxin. Nature 1985, 317(6034):267-270.

12. Gilbert HF: Protein disulfide isomerase and assisted protein folding. J Biol Chem 1997, 272(47):29399-29402

13. Chan DC, Kim PS: HIV entry and its inhibition. Cell 1998, 93(5):681-684

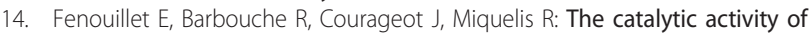
protein disulfide isomerase is involved in human immunodeficiency virus envelope-mediated membrane fusion after CD4 cell binding. J Infect Dis 2001, 183(5):744-752.

15. Barbouche R, Lortat-Jacob H, Jones IM, Fenouillet E: Glycosaminoglycans and protein disulfide isomerase-mediated reduction of HIV Env. Mol Pharmacol 2005, 67(4):1111-1118.

16. Barbouche $\mathrm{R}$, Miquelis $\mathrm{R}$, Jones IM, Fenouillet $\mathrm{E}$. Protein-disulfide isomerase-mediated reduction of two disulfide bonds of HIV envelope glycoprotein 120 occurs post-CXCR4 binding and is required for fusion. J Biol Chem 2003, 278(5):3131-3136.

17. Markovic I, Stantchev TS, Fields KH, et al: Thiol/disulfide exchange is a prerequisite for CXCR4-tropic HIV-1 envelope-mediated T-cell fusion during viral entry. Blood 2004, 103(5):1586-1594

18. Ryser HJ, Fluckiger R: Progress in targeting HIV-1 entry. Drug Discov Today 2005, 10(16):1085-1094.

19. Gowthaman U, Jayakanthan M, Sundar D: Molecular docking studies of dithionitrobenzoic acid and its related compounds to protein disulfide isomerase: computational screening of inhibitors to HIV-1 entry. BMC Bioinformatics 2008, 9(Suppl 12):S14.

20. Hatahet F, Ruddock LW: Modulating proteostasis: peptidomimetic inhibitors and activators of protein folding. Curr Pharm Des 2009, 15(21):2488-2507.

21. Ciminale V, Felber BK, Campbell M, Pavlakis GN: A bioassay for HIV-1 based on Env-CD4 interaction. AIDS Res Hum Retroviruses 1990, 6(11):1281-1287.

22. Lebon F, Ledecq M: Approaches to the design of effective HIV-1 protease inhibitors. Curr Med Chem 2000, 7(4):455-477.

23. Barbouche $\mathrm{R}$, Miquelis $\mathrm{R}$, Jones IM, Fenouillet $\mathrm{E}$ : Protein-disulfide isomerase-mediated reduction of two disulfide bonds of HIV envelope glycoprotein 120 occurs post-CXCR4 binding and is required for fusion. $\mathrm{J}$ Biol Chem 2003, 278(5):3131-3136.
24. Mandel R, Ryser HJ, Ghani F, Wu M, Peak D: Inhibition of a reductive function of the plasma membrane by bacitracin and antibodies against protein disulfide-isomerase. Proc Natl Acad Sci USA 1993, 90(9):4112-4116.

25. Naganawa S, Yokoyama M, Shiino T, et al: Net positive charge of HIV-1 CRF01_AE V3 sequence regulates viral sensitivity to humoral immunity. PLOS One 2008, 3(9):e3206

26. Trujillo JR, Goletiani NV, Bosch I, et al: T-tropic sequence of the V3 loop is critical for HIV-1 infection of CXCR4-positive colonic HT-29 epithelial cells. J Acquir Immune Defic Syndr 2000, 25(1):1-10.

27. Trujillo JR, Rogers RA, Brain JD: Shared antigenic epitopes on the V3 loop of HIV-1 gp120 and proteins on activated human T cells. Virology 1998 246(1):53-62.

28. Yang QE, Stephen AG, Adelsberger JW, et al: Discovery of small-molecule human immunodeficiency virus type 1 entry inhibitors that target the gp120-binding domain of CD4. J Virol 2005, 79(10):6122-6133.

29. Kimpton J, Emerman M: Detection of replication-competent and pseudotyped human immunodeficiency virus with a sensitive cell line on the basis of activation of an integrated beta-galactosidase gene. J Virol 1992, 66(4):2232-2239.

30. Jones $\mathrm{PL}$, Korte $\mathrm{T}$, Blumenthal R: Conformational changes in cell surface HIV-1 envelope glycoproteins are triggered by cooperation between cell surface CD4 and co-receptors. J Biol Chem 1998, 273(1):404-409.

31. Hombrouck A, Van RB, Michiels M, et al: Preclinical evaluation of $1 \mathrm{H}-$ benzylindole derivatives as novel human immunodeficiency virus integrase strand transfer inhibitors. Antimicrob Agents Chemother 2008, 52(8):2861-2869

32. Witvrouw M, Fikkert V, Pluymers W, et al: Polyanionic (i.e., polysulfonate) dendrimers can inhibit the replication of human immunodeficiency virus by interfering with both virus adsorption and later steps (reverse transcriptase/integrase) in the virus replicative cycle. Mol Pharmacol 2000, 58(5):1100-1108

33. Auwerx J, Stevens M, Van Rompay AR, et al: The phenylmethylthiazolylthiourea nonnucleoside reverse transcriptase (RT) inhibitor MSK-076 selects for a resistance mutation in the active site of human immunodeficiency virus type 2 RT. J Virol 2004, 78(14):7427-7437.

34. Stevens M, Pannecouque C, De CE, Balzarini J: Novel human immunodeficiency virus (HIV) inhibitors that have a dual mode of antiHIV action. Antimicrob Agents Chemother 2003, 47(10):3109-3116.

35. Svarovskaia ES, Barr $R$, Zhang $X$, et al: Azido-containing diketo acid derivatives inhibit human immunodeficiency virus type 1 integrase in vivo and influence the frequency of deletions at two-long-terminalrepeat-circle junctions. J Virol 2004, 78(7):3210-3222.

36. Zhang X, Pais GC, Svarovskaia ES, et al: Azido-containing aryl beta-diketo acid HIV-1 integrase inhibitors. Bioorg Med Chem Lett 2003, 13(6):1215-1219.

37. Lara HH, Ixtepan-Turrent L, Garza-Trevino EN, Rodriguez-Padilla C: PVPcoated silver nanoparticles block the transmission of cell-free and cellassociated HIV-1 in human cervical culture. J Nanobiotechnology 2010, 8:15.

38. Zussman A, Lara L, Lara HH, Bentwich Z, Borkow G: Blocking of cell-free and cell-associated HIV-1 transmission through human cervix organ culture with UC781. AIDS 2003, 17(5):653-661.

doi:10.1186/1743-422X-8-137

Cite this article as: Lara et al:: Antiviral propierties of 5,5'-dithiobis-2nitrobenzoic acid and bacitracin against T-tropic human immunodeficiency virus type 1. Virology Journal 2011 8:137. 